\title{
Analisa Tindak Tutur Dalam Tuturan Lara Pangkon Pada Upacara Temu Manten Masyarakat Kec. Ngantang
}

\author{
Trisnian Ifianti \\ IKIP Budi Utomo Malang \\ nianitubungas15@gmail.com \\ Enis Fitriani \\ IKIP Budi Utomo Malang \\ fitriaenis@gmail.com
}

\begin{abstract}
This study analyses Lara Pangkon's utterances at the ceremony of temu manten in Kec. Ngantang, in order to know the forms of speech acts, explain their meaning and how they are conveyed. In this research, the method used was descriptive qualitative research method, with the data source of this research is the utterances in Lara Pangkon as the main data source from and documentation books as additional data sources. In the end, this research shows that each form of speech delivered contains meanings and symbols that contain speech acts. After being studied, it can be concluded that from the 2 (two) parts of Lara Pangkon's possession, the speeches presented by both Pamasrah and Panampi contained 3 (three) expressive speech acts, 3 (three) directive speech acts, 3 (three) assertive speech acts and 2 (two) clear and commissive speech acts that can be conveyed briefly and straightforwardly.
\end{abstract}

Keywords: utterances, Lara Pangkon, Temu Manten Ceremony

\section{PENDAHULUAN}

Budaya adalah suatu tatanan hidup yang dinamis, berkembang dan dimiliki bersama oleh sebuah masyarakat dan merupakan warisan dari generasi ke generasi. Meskipun kadang budaya juga dipengaruhi oleh letak geografis suatu masyarakat tetapi keberadaan budaya dalam masyarakat tersebut masih dapat menunjukan ciri khasa daerah tersebut. Masyarakat kecamatan Ngantang adalah suku Jawa yang menempati Malang bagian barat lebih dekat ke Kediri dan Jombang. Sehingga adan kemiripan unsur budaya yang menjadi ciri khas kehidupan suatu masyarakat tersebut. Hal ini bisa di ketahui dari sumber-sumber tertulis, lisan dan gerak.

Pada masyarakat tradisional kegiatan mengaktifkan kebudayaan merupakan salah satu wujud nyata dari pewarisan tradisi dari kebudayaan itu sendiri. Hal tersebut misalnya pelaksanaan upacara tradisonal, misalnya upacara mitoni, tingkeban, sunatan, syukuran hingga temu manten, yang mana hal- hal tersebut menjadi sarana sosialisasi bagi suatu masyarakat. Tidak hanya mengaktifkan budaya dalam rangka menjaga budaya, tetapi juga merupakan sebuah sarana interaksi sosial yang tidak akan lepas dari interaksi lingual.

Salah satu unsur budaya yang paling utama adalah bahasa. Tetapi dalam hal ini, bahasa tidaklah dilihat sebagaimana yang dilakukan oleh linguistik umum, melainkan dilihat sebagai sarana interaksi atau komunikasi di dalam masyarakat. Setiap kegiatan budaya dalam suatu 
masyarakat tidak akan pernah meninggalkan yang namanya penggunaan bahasa. Pada upacara adat pernikahan misalnya, bahasa memegang peranan penting mulai dari diadakannya akad nikah sampai upacara temu manten itu sendiri.. Salah satunya acara Lara Pangkon pada upacara temu manten. Lara Pangkon adalah serangkaian acara yang bawakan oleh pihak penganten laki- laki yang di wakili oleh Pamasrah yang membawa Jagoan sebagai simbol dari pengantin lakilaki dan melakukan pencarian untuk mendapatkan pengantin perempuan, tuturan yang terdapat dalam Lara Pangon berisikan simbol- simbol bermakna yang menjadi nasehat bagi kedua penganten untuk mengarungi rumah tangga.

Searle (dalam Leech 2011:33) mengutarakan pendapat, bahwa dalam semua interaksi lingual mengandung tindak tutur atau kalimat dapat diwujudkan dalam prilaku tindak tutur (speech act). Ringkasnya, produk dari suatu kaliamat yang dalam kondisi tutur tertentu tindak tutur merupakan satuan kecil dari proses interaksi lingual. Tindak tutur bisa menjadi ukuran kemampuan seseorang dalam berkomunikasi. Pragmatik berkaitan erat dengan tindak tutur karena pragmatik mengkaji makna yang terkandung dalam kalimat dan kaitannya dengan situasi tuturan. Tindak tutur adalah salah satu kajian pragmatik yang erat kaitannya dengan makna, konteks dan komunikasi. Dalam hal ini tuturan dalam upacara adat harus sesuai dengan konteks agar makna tuturan yang disampaikan penutur dimengerti oleh petutur.
Tindak tutur tersebut masih menurut Searle (dalam Leech, 2011: 166) dibagi tindak tutur ilokusi dalam lima kategori, yaitu, asertif, direktif, komisif, ekspresif, dan deklaratif. Tindak tutur ilokusi yang di kaji dalam penelitian ini adalah tindak tutur yang masuk dalam kategori tersebut.

Tuturan dalam Lara Pangkon yang disampaikan pihak keluarga pengantin laki- laki (di wakili oleh Pamasrah) akan di sambut oleh pihak keluarga pengantin perempuan( diwakili oleh Panampi) di fragmenkan layaknya sebuah drama pendek yang diatur oleh protokol acara. Proses ini akan menceritakan tentang pencarian pasangan oleh pengantin laki- laki yang di simbolkan ayam jago dari awal hingga akhir nya mendapatkan pasangan yang di maksud. Tuturan yang terdapat dalam Lara Pangkon inilah yang di kaji berdasarkan teori Pragmatik, karena tuturan yang sampaikan oleh Pamasrah dan Panampi sebagai wakil pihak keluarga dalam upacara adat temu manten masyarakat Ngantang merupakan tindak tutur karena terjadi interaksi lingual dalam proses upacara adat tersebut.

Levinson mendefinisikan pragmatik adalah kajian bahasa yang mempelajari relasi bahasa dengan konteks ketika tuturan itu di utarakan. Sementara Parker (dalam Rahardi, 1986:48) pragmatik merupakan suatu kajian struktur bahasa secara eksternal. Dari apa yang diungkapkan oleh kedua tokoh tersebut, dapat di simpulakan bahwa pragmaktik merupakan suatu kajian yang berperan penting dalam 
menganalisa dan mendapatkan makna bahasa terhadap konteksnya. Pragmatik mengkaji bahasa dengan mempertimbangkan konteks agar dapat diperoleh apa maksud penuturnya. Kajian pragmatik memang harus berkaitan erat dengan konteks situasi tutur, sejalan dengan apa yang diungkapkan Leech (1993:8) bahwa "pragmatik adalah studi tentang makna dan hubungannya dengan situasi tutur (speech situations)". Menurutnya pragmatik menngkaji bagaimana bahasa dapat dipahami maknanya dalam sebuah interaksi dan pragmatik juga mengkaji makna dalam konteks dan bukan makna sebagai sesuatu yang niskala.

Kesimpulan dari paparan diatas adalah pragmatik merupakan ilmu bahasa yang mengkaji pemakaian bahasa, yang ditentukan oleh konteks situasi tutur di dalam suatu masyarakat dan adanya unsur kebudayaan yang menjadi wadah dan latarbelakang sehingga apa yang di ucapkan si penutur dapat dipahami si petutur.

Hal tersebut juga mendasari peneliti tertarik untuk mengkaji tindak tutur dalam tuturan Lara Pangkon dalam upacara temu manten masyarakat kecamatan Ngantang untuk memahami tindak tutur apa saja yang adala dalam tuturan tersebut dan makna apa yang terkandung di dalam tuturan Lara Pangkon tersebut sebagai upaya untuk menjaga keberadaan budaya Lara Pangkon masyarakat Ngantang.

\section{METODE}

Penelitian ini dilakukan di Desa Jombok Kec. Ngantang Kab. Malang. Dimana di tempat tersebut masyarakat masih mengadakan acara Lara Pangkon dalam upacara temu manten.Suatu penelitian tentu saja membutuhkan data yaitu keseluruhan hal yang dijadikan bahan penelitian. Karena penelitian ini bertujuan mendapatakan sejumlah data yang berbentuk lisan, maka yang menjadi sumber data adalah hasil wawancara dengan tetua adat dalam hal ini adalah pelaku Lara Pangkon pada upacara adat temu manten masyarakat kecamatan Ngantang. Metode yang digunakan adalah meode desktiptif kualitatif, dimana metode ini menjelaskan suatu keadaan secara apa adanya sesuai keadaan sebenarnya. Metode kualitatif merupakan metode yang paling cocok digunakan untuk mengembangkan teori yang dibangun melalui data yang diperoleh dari lapangan (Sugiyono, 2005: 23).

Adapun teknik pengumpulan data dilakukan dengan cara: (1) Melakukan observasi, yaitu dengan melakukan pendokumentasian atau merekam tuturan pada objek yang dikaji. Data akan diperoleh dari rekam simak prosesi Lara Pangkon dalam upacara temu manten. (2) Teknik interview, yaitu dengan melakukan wawancara kepada informan yaitu tokoh masyarakat/ tetua pelaku Lara Pangkon, dimana interview yang dilakukan secara tidak terstruktur yaitu pertanyaan tidak ditentukan/dibatasi sebelumnya, sehingga peneliti memberikan kebebasan kepada informan untuk menjawab atas setiap 
pertanyaan yang dikaji. Sehinga akan diperoleh jawaban sebagai data mengenai bagaimana posesi dan tuturan Lara Pangkon dalam upacara tersebut. Teknik analisis data dalam penelitian ini dengan teknik dokumentasi dan analisis data mengidentifikasi data yang sederhana sehingga lebih mudah dibaca dan di kaji maknanya. Data yang terkumpul dari hasil rekaman maupun hasil wawancara lapangan diarsipkan kemudian ditranskripkan ke bentuk tulisan dan yang diterjemahkan ke dalam bahasa Indonesia untuk mempermudah analisa, mengklasifikasi tindak tutur dan menganalisis makna maupun bentuk tindak tutur kemudian menyimpulkan hasil penelitian kemudian masalah penelitian akan terjawab.

\section{HASIL DAN PEMBAHASAN}

Sumber data hasil rekam catat akan melalui tahap- tahap klasifikasi, kemudian dilanjutkan dengan merubah rekaman dan hasil wawancara kedalam bentuk tulisan dan kemudian diterjemahkan ke bahasa Indonesia. Data tersebut kemudian diklasifikasikan dan dianalisa atau dirangkum sebagai hasil penelitian. Data yang dianalisa peneliti adalah bagian dari tuturan Lara Pangkon yaitu bagian Pambuka dan Paneges. Dari hasil analisis data yang dilakukan dapat dipaparkan bentuk/kategori dan makna tindak tutur.

Bagian Pambuka dalam Lara Pangkon adalah bagian pengenalan. Pada bagian ini Pamasrah selaku wakil dari pihak pengantin perempuan mendatang rumah pihak pegantin perempuan yang di yakini sebagai pasangan dari pengantin laki- laki. Pamasrah dengan membawa ayam jago terbuat dari kayu sebagai simbol dari penganting laki- laki diikuti banyak oarang sebagai pengiring. Pada bagian ini tutran nya berisikan perkenalan dan penjelasan keberadaan si Jago( simbol penganti laki- laki). Tuturan ini disampaikan dengan tujuan memberitahukan bahwa ada Jago( pengantin lakilaki) yang sedang mencari pasangan.

Data 1

Pamasrah: "Assalamualaikum." Panampi : "Waalaikumsalam.

Tejo-tejo sulaksono, tejone wong anyar katon. Ilang tejane cumlorot saksodo lanang, jumleger kari menungsone. Dherek, niku sinten namine?"

Pamasrah: "Nami kulo Pak Cukup, yogane Pak Turah. Tegese cukup sing disandang lan dipangan nganti turahturah."

Panampi : "Lha sampeyan niki saking pundi pinangkane?"

Pamasrah: "Kula saking Suroloyo Adilinuwih. Suro tegese wani, loyo pati, adi bagus, linuwih samubarang kalire. Lajeng panjenengan meniko sinten, lan niki dusun pundi?",

Panampi : "Nami kulo Darmojulig. Darmo niku temen, Julig niku 
duta perwakilan, lan niki dusun Karang

Kadempel. Tebih saking Suroloyo dumugi Karang Kadempel mriki, menopo ingkang sampeyan padosi, Dhik?

Tuturan diatas juga menunjukkan bagaimana pemakaian tuturan ekspresif yang di ucapkan dengan hormat. Pada bagian Pambuka ini,bisanya di ucapkan salam dan perkenalan. Dalam hal ini pihak keluarga pengantin perempuan yang di wakili oleh Panampi menyakan perihal kedatang pihak keluarga penganti laki- laki yang di wakili oleh Pamasrah dengan rombongan pengiring nya membawa jago sebagai simbol pengantin laki- laki. Pada data diatas tampak bahwa tindak tutur ekspresif menyapa/ bentuk penghormatan, yaitu dengan adanya tuturan salam dan juga memperkenal kan diri.

Data 2

Panampi : "Lha nggih niki Dhik, sing sampeyan padosi. Cocok nggih niki." Pamasrah: "Niku jenenge mapan kabeneran, dapur kaleresan."

Panampi: "Wonten paribasane, tumbu oleh tutup, bantal oleh guling. Tebih saking Suroloyo, liwat dalan pundi sampeyan wau, Dhik?

$\begin{array}{rrr}\text { Tuturan } & \text { diatas } \quad \text { juga } \\ \text { menunjukkan } & \text { bagaimana }\end{array}$

pemakaian tuturan asertif yang di ucapkan bertujuan untuk menerima kedatangan dari pihak pengantin laki- laki. Pada kalimat " Niku jenenge mapan kebeneran, dapur keleresan" memiliki arti "sangat tepat", atau " kebetulan sekali". Dalam konteks ini dimaksudkan bahwa kedatang pihak pengantin laki- laki adalah suatu hal yag tepat dan sangat kebetulan karena pihak pengantin perempuan juga sedang mencari pasangan. Pemakaian tuturan asertif yang tepat tersebut menyatakan bahawa kaedua pihak saling menerima.

\section{Data 3 \\ Panampi : "Lha condrone jago sampeyan niku napa, Dhik? Sampeyan terangaken siji-siji." \\ Pamasrah: "Siji-siji? Nopo mawon, dugi pundi sing sampeyan takokaken? Kula jawabe."}

Tuturan diatas adalah tuturan kategori komisif yang merupakan pernyataan menjajikan. Pada kalimat " siji- siji?, nopo mawon, dugi pundi sing sampeyan takoaken? Kulo jawabe", memiliki arti bahwa apapun satu persatu pertanyan dari si Panampi, semua akan di jawab denagn jelas oleh Pamasrah. Dalam konteks ini tuturan komisif telah di ungkapkan yaitu menjajikan jawaban dari semua pertanyaan si Panampi.

Data 4

Pamasrah: "Manco warno."

Panampi : "Lho, kok saged manco warno? Nopo mawon dumununge?" 
Pamasrah: "Ono putih, ono abang, ono ireng, ono kuning."

Panampi: "Lha maknane nopo, cubo sampeyan terangaken siji siji?"

Tuturan diatas adalah tuturan dengan kategori asertif , penolakan jawab dari Pamasrah karena Panampi meragukan jawaban tersebut. Kata " lho, kok saged manco warno? Nopo mawon dumununge?", artinya mengapa bisa aneka warna, bagaimana bisa, adalah tuturan asertif yang menunjukkan kesopanan dalam menolak penjelasan sesorang dalam hal ini Pamasrah.

Data 5

Panampi: "Pitik sampeyan niku dereng nate tarung tah, Dhik?" Pamasrah: "Lho, dereng nate."

Data di atas merupakan bentuk tuturan kategori ekspresif dengan maksud mengkritisi semua penjelasan dari Pamasrah. Setelah dijelaskan semua unsur- unsur kebaikan yang ada dalam si jago( simbol pengantin laki- laki), Panampi merasa ada yang kurang dari penjelasan si Pamasrah. Sehingga untik mengkiritisi itu di ungkapkan dengan tuturan ekspresif sebagai kritikan dari penjelasan Pamasrah .

Data 6

Pamasrah: "Dalem madigondo, bantal piwarah, kemul pitutur, dene kurungane lair lan batin, mudune jengkar guling kursi gading."

Panampi : "Lha kok jago sampeyan mboten saged kluruk, Dhik?"

Pamasrah: "Nggih saged.

Cuma saumur

kluruk pisan tok.

Kluruke wayah jam

wolu esuk, metu

nduk ayunane

sidodadi, diapit lan

diadep para priyayi,

diwulang bapak

naib.'

Tuturan dia tas berarti pujian yang di lontarkan oleh Pamasrah kepada si jago( simbol pengantin laki- laki). Tuturan ini masuk dalam kategori ekspresif yaitu menyampaikan pujian. Kalimat tersebut memiliki arti pujian yang mengedepankan kebaikan dari si jago( penagntin laki- laki) sehingga di pilihlah kalimat yang tepat untuk menyampaikan pujian tersebut.

Data 7

Panampi: "Nek ngaten amrih saene, ayo seduluran kalih kulo. Jago sampeyan kulo pek'e."

Pamasrah: "Lho empun ndeder perkoro lho, nggih? Pengin ngepek jago kulo, kulo rewangi pecahe jojo wutahe ludiro."

Tuturan dia atas artinya adalah penolakan. Ketika Panampi ingin meminta si jago ( pengantin laki- laki) untuk di pelihara( diambil menantu), Pamasrah dengan halus menolak. Tuturan ini msuk dalam kategori asertif yaitu pernyataan penolakan. Kata "Lho empun ndeder perkoro lho, nggih? Pengin ngepek jago kulo, kulo rewangi pecahe jojo wutahe ludiro" berarti " jangan membuat perkara, mau ambil jago saya, akan saya bela sampai titik darah penghabisan" merupakan 
penolakan .

Kemudian analisa pada bagian kedua yaitu bagian Paneges - Bagian Peneges ini mempunyai makna yaitu bagian dimana setelah di kenalkan dan di jelaskan kehebatan si Jago ( pengantin lakilaki) Panampi sebagai wakil kelaurga pengantin perempuan benar- benar ingin memiliki si jago( simbol pengantin laki- laki). Sehingga setelah melakukan perebutan di gambarkan dengan pertunjukan pencak silat pendek, Pamasarah menegaskan kembali bahwa si jago ini memnag layak dimiliki pihak pengantin putri dengan syarat dan ketebtuannya. Terdapat 1( satu) tuturan komisif, dan 3( tiga) tuturan direktif.

Data 8

Pamasrah: "Nggih niki jagone kulo sukakaken sampeyan, tapi mboten gampang kula sukakaken lho. Wonten tebusane."

Panampi: "Lha nopo tebusane?"

Tutuaran diatas adalah tuturan meminta / perjanjian. Kalimat " tapi mboten gampang kulo sukaken lho, wonten tebusane" memiliki arti jago akan diberikan tapi tidak mudah, harus ada tebusan nya. Makna dari tuturan ini adalah meminta kesepakatan untuk menyanggupi tebus yang dimaksud. Tuturan ini masuk dalam kategori tuturan komisif, yaitu meminta perjanjian kesepakatan.

Data 9

Panampi: "Nek wonten kemanten lanang, kudu wonten kemanten wedok, nek mboten wonten waline?"

Pamasrah : "Mboten dadi, Dherek."

Tuturan tersebut masuk dalam kategori direktif, yaitu meminta persetujuan atas pernyataan. Kalimat tersebut dikemukakan secara halus sebagia permintaan persetujuan atas pernyataan sebelum nya.

Data 10

Panampi : "Napa mawon isine?"

Pamasrah: "Gedang minongko sajen, tegese gegedo lan padango pikire, ngajenono awake. Kupat lepet ngluwaro nadare, ngluwarono sengkalane, netepano agamane, cedakno rejekine, adohno bilahine."

Tuturan " cedakno rejekine, adohno bilahine" memiliki arti “ dekatkan rejekinya, jauhkan halangan nya" merupakan makna daripada penharapan, memohon atau mendoakan agar dalam mengarungi rumah tangga kedua pengantin senantiasa didekatkan rejekinya dan dijauhkan halangan nya. Tuturan ini masuk dalam kategori direktif.

Data 11

Panampi : "Wah, nek ngaten empun ngerti sedoyo kulo, jelenterehe."

Pamasrah: "Sampun kulo jelentrehaken sedoyo. Sakniki kulo titip jago niki minongko anak kulo lanang." 


\section{Panampi : "Nggih, Dhik, kula tramine sampeyan sekseni."}

Pernyataan di atas adalah tutran yang bermakna meminta persetujuan untuk menyaksikan pemberian si jago( simbol pengantin laki- laki) kepada pihak keluarga pengantin perempuan. Tuturan diatas masuk dalam kategori direktif yaitu meminta persetujuan untuk disaksikan penyerahan si jago tersebut.

\section{PENUTUP}

Seperti yang telah paparkan pada latar belakang masalah bahwa tuturan yang yang di sampaiakn dalam posesi Lara Pangkon, penyampaiannya dilakukan oleh Pamasrah dan Panampi yang isi atau makna serta tujuan adalah untuk memberikan gambran perjalanan kedua pengantin dalam mengarungi rumah tangga. Data yang di peroleh dari observasi dan interview telah dianalisa, adalah merupakan tuturan yang telah diklasifikasikan sesuai kategori dari tuturan tersebut. Hasil dari penelitian ini adalah: (1) Tindak tutur menyapa/bersalam merupakan tuturan klasifikasi tindak ilokusi masuk dalam kategori tuturan ekspresif. (2)Tindak tutur meminta merupakan tuturan kalisifikasi tindak ilokusi berkategori tuturan direktif. (3) Tindak tutur menenerima dan juga menolak pernyataan merupakan tuturan klaisifikasi tindak ilokusi dan kategorinya adalah tuturan asertif. (4) Tindak tutur menyanjung dan mengkritisi merupakan tuturan kalisifikasi tindak ilokusi ketegori ekspresif. (5) Tindak tutur meminta

$\begin{array}{lrr}\text { penjelasan merupakan } & \text { tuturan } \\ \text { klasifikasi ilokusi } & \text { degan } \\ \text { penyampaiannya masuk } & \text { dalam } \\ \text { tuturan kategori direktif. } & \end{array}$

\section{DAFTAR PUSTAKA}

Arikunto, Suharsimi.2003. Prosedur Suatu Pendekatan Praktik. Jakarta: Asdi Mahasatnya.

Hamid Hasan Lubis, H.A. 1991. Analisis Wacana Pragmatik. Bandung, Angkasa.

Levinson, Stephen C. 1993. Pragmatics. Cambridge : Cambridge University Press.

Leech, Geoffry. 1993. Prinsip-

Prinsip Pragmatik. Jakarta. Universitas Indonesia.

Leech, Geoffrey. 2011. PrinsipPrinsip Pragmatik. (edisi terjemahan M.D.D Oka) Jakarta: Universitas Indonesia Press.

Nader, F.X. 2008. Pragmatik dan Penelitian Pragmatik. Yogyakarta. Graha Ilmu. Rahardi, Kunjana. 2005. Pragmatik Kesantunan Imperatif Bahasa Indonesia. Yogyakarta: Erlangga.

Sugiyono. 2005. Memahami Penelitian Kualitatif. Bandung: Penerbit CV Alfabeta 